The duration of the condition must be said to be not less than three years, for he says that when he was refracted in the hospital and prescribed glasses; the doctors found the right eye not quite up to the mark, even at that time.

\title{
ANNOTATION
}

\section{Instruction for Medical Students in the Treatment of Ophthalmia Neonatorum}

In July, 1932, there was an annotation in our pages on the subject of instruction for medical students in the treatment of ophthalmia neonatorum. The attention of the General Medical Council had been drawn to this subject by a resolution passed at the Annual Meeting of the British Medical Association in 1931.

Ever since St. Margaret's Hospital was opened in September, 1918, it has been obvious that special facilities for instructing students and midwives in the treatment of this dread ophthalmic disease were available. The midwife students were not slow to avail themselves of the opportunity; but it is only during the past year that any considerable body of medical students has availed itself of the privilege, as is shown in the Report on page 238.

The Council of British Ophthalmologists has for some years past urged that some compulsory instruction in the treatment of ophthalmia neonatorum should form part of the medical students' curriculum. We understand that the result is largely due to the interest taken by the L.C.C. in the memoranda which have been placed hefore it by the Council of British Ophthalmologists and by Mr. Mayou. All concerned are much to be congratulated on the successful result of the past five years' work.

\section{ABSTRACTS}

\section{I.-GENERAL MEDICINE}

Garland, Hugh G. and Thompson, J. G. (Leeds).-Uveoparotid tuberculosis. (Febris Uveo-Parotidea of Heerfordt). Quart. Jl. Med., (New Series), Vol. II, No. 6, pp. 157-177, April, 1933.

This joint contribution by Garland and Thompson, physician and pathologist respectively, to the literature of uveo-parotid fever, 
is a notable addition and should serve by its locus and its importance to draw the attention of physicians to this not very widely known condition.

The paper includes an analysis of 46 cases besides their own, a case report, clinical and autopsy, of their female patient of 28 years, and a fairly detailed survey of the assumed or proved aetiology in many of the already published cases. The authors are so convinced of the invariable rôle of tubercle that they venture to alter the name of this well-defined clinical and pathological entity from Heerfordt's febris uveo-parotidea to uveo-parotid tuberculosis. Some will doubt the wisdom of changing the name, but the authors have stated a strong case in support of the view, held by many, that tubercle is the most important, if not the only factor, in this disorder.

The ophthalmic interest in the present case is that acute painful iridocyclitis of the right eye was followed a week later by bilateral painless enlargement of the parotids, and then five weeks later by iritis of the left eye. Total posterior synechiae and keratitis punctata in the right eye are noted. The patient died four to five months after the start of the eye trouble, death being due to miliary tuberculosis and massive, non-caseating tuberculosis of the heart wall, especially the right ventricle. The finding of this special kind of myocardial tuberculosis, itself a very uncommon condition, along with miliary tubercle, makes this case resemble closely one reported by Souter in the Trans. Ophthal. Soc. in 1929, pp. 113-128, in which tubercle bacilli were recovered from the heart muscle.

The present comprehensive article is beautifully illustrated, showing the appearances of the myocardial changes and those in the parotids, and can be recommended to anyone desirous of ready access to what has been found in those cases already published.

Clark Souter.

\section{II.-OPTICS AND REFRACTION}

\section{(I) Meyer, Max F. (St. Louis).-Mechanism of accommodation studied experimentally. Arch. of Ophthal., July, 1932.}

(1) Meyer points out that theoretically there are three different mechanisms which may alter the curvature of the lens within the eye. (1) Radial pull applied to its circumference. (2) A contracting force applied to its circumference and acting towards the axis. (3) Hydraulic pressure, applied to one of its surfaces, provided that the yielding of its peripheral parts is more obstructed than the yielding of its central parts. The first and second mechanisms have already 
been invoked to explain accommodation in the current theories but the third has not received the consideration it deserves. A model made with a gelatine lens shows how the focus of this is shortened when pressure is exerted on one face, if the peripheral parts are more supported than the central. In the eye, when the ciliary muscle contracts, its radial fibres draw the choroid forwards and thus diminish the volume of the vitreous chamber. At the same time, the iris stiffens and the pupil diameter diminishes by contraction of the sphincter iridis. The effect of this is to squeeze the lens forward, so to speak, through the pupil and thus to increase the convexity of its anterior surface. One would, of course, expect the convexity of the posterior surface to be diminished at the same time, and possibly by the same amount, but the author shows by an interesting piece of mathematics that when pressure deformation of this type occurs in a flexible asymmetrical lens, the front surface gains vastly more in curvature than the rear surface loses. The author's theory thus explains also the value of the asymmetry in curvature of the two surfaces of the lens in the eye.

F. A. W-N.

(2) Ames, A. (Junr.) Ogle, Kenneth N. and Gliddon, Gordon $\mathbf{H}$. (Hanover).-Corresponding retinal points, the horopter and size and shape of ocular images. Jl. of Obt. Soc. of Amer., October and November, 1932.

(2) These two papers, an amplification of work already noticed in this Journal (February, 1933, p. 105), are technical in character, and in parts difficult of comprehension except by those who have special training in this branch of optics. The work reported is concerned largely with the horopter "that surface in space, every point of which is imaged on corresponding retinal points" (in the two eyes), and various methods are used to determine the shape of this surface, or rather of its horizontal section. This latter is found to vary in different subjects and its position relative to the fixation point to be affected by factors such as eso- and exophoria.

The authors find that the relationships between subjective and objective space and directional values are subject to more exact measurement than has heretofore been recognised and that in consequence of these measurements "the fundamental hypothesis of specific directional values associated with specific brain centres is placed on a firmer basis."

F. A. W-N. 


\section{III.-TRACHOMA}

(I) Wilson, Rowland (Egypt).-Experiments on preventive treatment of trachoma and acute ophthalmias. Seventh Annual Report of the Giza Memorial Ophthalmic Laboratory. Department of Public Health, Cairo. 1932.

(1) During the past three years a serious attempt has been made to find some satisfactory prophylactic treatment for trachoma and acute ophthalmia, which would be applicable to the population of a village of about 3,000 inhabitants; and such a village near Cairo was selected for experimentation.

First of all it was decided to ascertain the effect of the regular use of eye drops by the whole population. With this in view a quantity of "blue eye-drops" with eye-droppers was supplied to every house in the village. These blue eye-drops have been in use in Egypt for 30 years. They consist of a solution containing 0.5 per cent. of zinc sulphate coloured with 0.01 per cent. of mercury pyroctanate; this gives a stable solution with a distinctive colour.

A responsible person in every house was instructed in the use of the drops and a trained nurse gave personal instruction to all the mothers in their use. The people were requested to use the drops twice daily for themselves and especially for their children, and as far as possible the nurse visited the homes of the people to see that the treatment was being carried out. At first the people were delighted with the free issue of drops, but they soon became careless and the experiment ended in failure owing to their lack of interest and inability to appreciate the importance of the experiment.

Secondly, it was decided to select a number of children and treat them from birth onward. It was explained to the mothers of the children that the treatment was being carried out in order that every child should grow up with good eyes, and to effect this it was necessary that they should have daily treatment. All the necessary arrangements were made to carry out the experiment, but it was not long before the attendances became very irregular, while some did not attend at all.

As a next step about 12 infants were put under similar treatment, but this time a trained employee was paid to visit the homes of the people in order to instil the drops himself. Even this scheme failed as people began to absent themselves from their homes and others objected to the treatment on the ground that their children were being experimented on.

Finally, when these measures had failed and caused no little 
discouragement it was decided to pay a half-penny (two milliemes) a visit to any mothers who would bring their children for regular treatment. This scheme proved most successful. Only ten newborn children were selected from numerous applicants and they have attended regularly ever since.

Five of these ten children received drops of trypaflavine ( 1 in 5,000 in castor oil) in both eyes regularly but all developed trachoma sooner or later; nor did these drops prevent attacks of acute KochWeeks conjunctivitis.

The other five cases were treated with the "blue drops" mentioned above, and these have responded much more encouragingly to treatment. Only one of these developed trachoma and that after nine months, while the other four have remained free from trachoma for a year. This is remarkable considering that these children are living amidst the dust, dirt and unhealthy surroundings of a typical village and are constantly exposed to infection. Furthermore, previous observations have shown that the average age at which trachoma appears is before six months. However, the above treatment did not prevent attacks of KochWeeks conjunctivitis, though these were slight.

It is obvious that the method of prophylaxis finally employed is impracticable on a large scale, but it is of great importance in indicating that a very simple form of treatment may be capable of warding off trachomatous infection.

\section{A. F. MacCallan.}

(2) Stewart (Egypt).-Prowazek-Halberstaedter bodies. Seventh Annual Report of the Giza Memorial Ophthalmic Laboratory. Department of Public Health, Cairo. 1932.

(2) The Prowazek - Halberstaedter bodies (Halberstaedter Prowaczek Körperchen usually abbreviated as H.P.K., though the author abbreviates otherwise) is an inclusion found in the epithelial cells of the conjunctiva. It has been seen in man, certain monkeys and the pig. In its fully developed state it consists of a mass of minute granules lying in a vacuole in the cytoplasm. The granules are not free in the vacuole but are embedded in a ground substance which, when stained with Giemsa's solution, is of a vivid royal blue colour, while the granules are either blue or red.

H.P.K. have been found in trachoma, gonococcal and nongonococcal conjunctivitis of the new-born, and of adults, in the epithelium of the urogenital tract of parents of similarly affected infants, in swimming-bath conjunctivitis, in the conjunctivitis of swine-fever and have been described as causative of some of these conditions. 
According to Stewart the following stages can be recognized in the development of H.P.K.:-Free bacterium taken up by epithelial cell; bacterium cased in plastin and partially digested (i.e., initial body); groups of bacteria in the same state (i.e., fused initial bodies); coarsely granular and finely granular stages of phagocytic digestion; H.P.K. with larger blue, smaller blue, and red granules (i.e., elementary granules). Persistence of inclusions is due to persisting bacterial infection. There is no proof that initial bodies or elementary granules multiply.

As the result of his researches the author has no doubt that H.P.K. are formed by phagocytosis of pathogenic bacteria by epithelial cells. He has traced the transition from free bacteria to the complete inclusion. These inclusions do not occur in uncomplicated trachoma. They are found in conjunctivitis caused by the following bacteria : - gonococcus, pneumococcus, Koch-Weeks bacillus, diplobacillus of Morax-Axenfeld and streptococcus haemolyticus. If trachoma is accompanied by conjunctivitis due to one of these organisms then H.P.K. are usually found.

The inoculation of trachomatous material from man to man is almost always followed by a more or less acute conjunctivitis which precedes the development of the signs of trachoma; here H.P.K. are found since there is always a bacterial infection apart from the trachoma.

The inoculation of trachomatous material from man to monkey, when successful, results in a chronic follicular conjunctivitis which is trachoma or a trachoma-like condition without the development of acute conjunctivitis because the conjunctival flora of man, as a general rule, cannot exist on the monkey's conjunctiva ; in these cases no H.P.K. are found; if they do appear they are due to secondary bacteria exalted by the toxic inoculation.

Some original and excellent pictures of H.P.K. accompany this important paper.

A. F. MacCallan.

(3) Morax (Paris). - Microbiological aetiology of trachoma. (Etiologie microbiologique du trachome.) Rev. Internat. du Trach., Juillet, 1933.

(3) It is generally agreed that bacteriological examination of the conjunctival secretion in trachoma has not supplied any positive indication as to the aetiology of the disease. Examination of the epithelial cells, obtained by scraping the conjunctiva, has given rise to much discussion since in 1907 Halberstaedter and Prowaczek described the occurrence within the cells of curious corpuscular appearances in trachoma in man and also in certain monkeys in which the conjunctiva had been inoculated with human 
trachoma. These Halberstaedter - Prowaczek Körperchen are referred to as H.P.K.

H.P.K. require suitable staining to render them suitable for examination under the microscope. They are found much more readily in trachoma of recent date than in old cases in which they may be absent.

The late Professor Axenfeld, in his report on the aetiology of trachoma prepared for the abortive International Congress of Ophthalmology at St. Petersburg in 1914, considered H.P.K. to be the infective agent in trachoma. Ophthalmologists forgot all about this when Noguchi announced his discovery of the cause of trachoma in his bacterium granulosis. When this was exploded ("depuis l'effondrement de ces microorganisms ") the upholders of the H.P.K. theory of the causation of trachoma returned to the lists, though without any further increase in their armament.

Since then H.P.K. have been found in ophthalmia neonatorum, both gonococcal and non-gonococcal, in epitheliosis desquamativa conjunctivae of Samoa, in the conjunctivitis of swine-fever and in swimming-bath conjunctivitis.

The existence of H.P.K. in trachoma cannot be doubted any more than its parasitic nature (" pas plus que leur nature parasitaire "). As for its rôle in the causation of trachoma, this can only be looked upon as theoretical.

\section{A. F. MacCallan.}

(4) Olitsky, Peter K., and Tyler, Joseph R. (New York).Trachoma in Egypt. Arch. of Ophthal., October, 1933.

(4) Olitsky and Tyler made various experiments to try and find a hitherto undescribed microbic or ultra-microscopic cause for trachoma and were unsuccessful. Even inclusion bodies were not found except in cases complicated by secondary infections with bacteria such as the bacilli of Koch-Weeks or MoraxAxenfeld, or pneumococci, streptococci or gonococci. Bacterium granulosis, however, was found by cultivation from the tarsal cartilages removed from cases of trachoma. The organism demands a special culture medium, and in the early stages of its growth is easily swamped out by other bacteria. Only one to four colonies of B. granulosis could be found on the initial culture plate, hence its presence is easily overlooked. The organism has definite cultural and serological characteristics which enabled the authors to identify it with that described by. Noguchi; when inoculated into monkeys, it produced a granular conjunctivitis.

F. A. W-N. 
(5) Bussola (Milan).-Examination of the blood and the capillaries in trachomatous subjects. (Ricerche ematologiche $e$ capillaroscopiche sul trachoma).' Rass. Ital. d'Ottal., MarchApril, 1933.

(5) Bussola has examined the blood in 100 cases of trachona. $\mathrm{He}$ finds that in about half the cases there is slight defect of haemoglobin and a number of red blood plates below normal. About the same number showed a reduction in the number of white corpuscles, but there was generally an excess of eosinophils. This finding suggests an underaction of the haemopoietic organs. The investigation of the capillaries was made on the epiungual fold of the left ring finger. The appearance of the capillaries is to all intents normal. The loops of the capillaries are generally visible, few in number with short, irregular, but not tortuous, arterial and venous vessels. There are seldom any anastomoses; the intercalary region is usually a little tortuous and varicose, but seldom much convoluted. These appearances point to general exudativelymphatic diathesis.

Harold Grimsdale.

(6) Vele (Parma).- - Trachoma in Parma between r921-1932. (II tracoma nella citta e nella provincia di Parma nel dodicennio I921-I932). Lett. Oftal., March, 1933.

(6) Trachoma appears, according to Vele, to have been unknown in Parma before the return of the soldiers from Napoleon's campaign in Egypt. Once established, the disease spread rapidly through the crowded quarters of the city and became a serious menace. Though preventative measures were attempted, little progress was made before the establishment of Fascism with its special care for public health. As a result of various methods, improvement in hygiene and diffusion of knowledge, there has been great reduction in the number of cases, so that the proportion of trachomatous patients to the local clinic has fallen from 8.33 per cent. in 1921 to 2.59 per cent. in 1932.

Harold Grimsdale.

(7) Cusumano (Palermo).- Trachoma and diathesis: treatment by autogenous and stock vaccine. (Tracoma e costituzione ed autovaccinoterapia). Rass. Ital. d'Ottal., SeptemberOctober, 1933.

(7) It has been held for a considerable time, especially by Angelucci, that trachoma is an expression of a general diathesis rather than a contagious disease; Cusumano thinks it certain that the disease, even if it is contagious, cannot be transmitted unless the recipient has already the predisposition towards it. 
The more serious effects that are seen in the cases of old trachoma are due, not to the trachoma, but to intercurrent infections by other micro-organisms. This has been proved by the experiences of Ruata, who has established that if other infections are avoided trachoma runs a benign course. The application of auto-vaccines or of stock polyvalent vaccine to the surface of the eye is able to bring about a rapid improvement in the secondary lesions and to effect a cure much more rapidly than when the older methods of treatment are employed. So far as the primary process is concerned, it has little effect.

It would seem certain that there must be some specific cause of trachoma as well as the lymphatic diathesis. Here in London there are plenty of children who suffer from adenoids, but trachoma is quite rare. Whether Noguchi's bacillus is the true cause or not, there can be little doubt as to the contagious nature of the disease.

Harold Grimsdale.

\section{VI.-MISCELLANEOUS}

(1) Parsons, Sir John (London).-Developmental myopia and the treatment of myopes. Lancet, October 7, 1933.

(1) In this short article Parsons seems to have succeeded in putting the principal known facts about myopia into the proverbial nutshell, a most difficult thing to do when one considers the constant swing of the pendulum from one side to the other in connexion with this elusive subject. He first states the principal theoretical causes to be :-(1) Abnormal length of the eyeball; (2) Abnormal curvature; (3) Abnormal refractive indices of the media; (4) Displacement forwards of the lens ; and (5) A combination of these factors. The author admits as true the usual generalization that the infant is hypermetropic and tends during the early years of life to become less so. After discussing certain statistical facts regarding the normal and the ideal normal he passes to the consideration of cases which may be counted as normal, though not in the class of ideal normality for human beings (emmetropia). "It would seem certain that from the biological point of view we should expect to find many examples of permanent low hypermetropia, and a few-but perhaps not negligible-examples of permanent low myopia. Such cases are fundamentally no more pathologically abnormal than short men or tall men."

There is a class of children with very low myopia whose myopia increases during growth up to a maximum of one or two dioptres. This state of affairs the author regards as developmental and not 
as abnormal, but for the complete argument readers should go to the original. The reviewer hopes he correctly interprets the author's view in saying that while such children should certainly constantly wear their correction mainly in the interest of mental development they should not be too much restricted as regards near work. It is understood that all such children be, nevertheless, kept under observation. "If there are cases of "stationary" myopia such as I have suggested, they are eminently suited for such occupations (i.e., involving near work), since there is no reason to suppose they would suffer in any way. I think the evidence is in favour of the view that degrees of myopia (e.g., of 4 or $5 \mathrm{D}$.) which I have not ventured to include in the above category, may yet suffer no detriment whatever from a considerable amount of near work." The author next passes to the treatment of high myopia. He is entirely in favour of the "myope" class, but deprecates the enthusiasm which outruns discretion. "Many of these patients are advised to adopt a régime and mode of life which is as ill-judged as to advise a poor patient to winter on the Riviera. In cases of progressive myopia the evidence is overwhelming that near work, especially when prolonged or carried out under unsatisfactory conditions, tends to aggravate the disease -for these are cases of disease-therein differing from what I have called developmental myopia." The author's article occupies only four columns of the Lancet, but it should be read by everyone interested in the problems of myopia, and that is to say by every oculist.

ERnest Thomson.

(2) Motolese (Florence).-The surgical treatment of high myopia. (Il trattamento chirurgico nella miopia elevata). Boll. d'Ocul., November, 1933.

(2) Motolese, in this long paper, gives an historical account of the operation of removal of the lens in high myopia and of certain other procedures which have been suggested from time to time by various surgeons with the aim of stopping the progress of the disease. He discusses the change in refraction which will follow the removal of the lens in high myopia and gives tables to show the correcting lens which will be required with the varying curvature of the cornea and length of the eye. Finally, he records the results of operation on 32 patients; from these he draws the following conclusions :-(1) That removal of the lens in properly selected cases is of great advantage in that it renders high myopes independent of glasses; (2) And is almost always productive of an increased acuity of vision; (3) He does not think there is any increased danger of detachment of the retina and (4) $\mathrm{He}$ holds that it has a good influence on the progress of myopia. 
As regards the selection of cases, it should be limited to myopes of more than $-16 \mathrm{D}$.; the method of election is discission followed by removal of the broken up lens matter.

Harold Grimsdale.

(3) Duke-Elder, Sir W. S. (London). - Modern methods of treatment in ophthalmology. Practitioner, October, 1933.

(3) The treatment of infective lesions of the uveal tract has made considerable advances during recent years and depends to some extent on the recognition of the importance of allergy in ocular inflammations.

It has long been known that many infections of the eye depend upon the existence of infective foci elsewhere in the body, in so far, at any rate, that in many cases the removal of the focus is followed by a resolution of the ocular lesion. A considerable amount of experimental work has been done during recent years bearing on this subject, the stimulus for which has been an attempt at the establishment of evidence for the theory of elective localization of certain organisms in individual tissues. There is no doubt that organisms in the blood-stream can excite an ocular inflammation, and that such an infection can produce a state of hypersensitivity in the ocular tissues. Once such a hypersensitivity has been developed, any late contact of the sensitized eye with the specific bacterial products results in the renewal or recrudescence of the ocular inflammation, a condition of things quite comparable to that occurring clinically from foci of infection occurring elsewhere in the body. In this event it is seen that the stage is occupied not so much by the bacteria as by the local allergic state to which their presence has given rise, and treatment must therefore be directed accordingly.

Duke-Elder recognizes that allergic conjunctivitis is a very common condition, and that its treatment is difficult. In the cornea, interstitial keratitis seems frequently to be allergic in nature. The cornea is sensitized by the direct invasion of treponemes in foetal or very early life, and a later liberation of syphilitic virus produces an intoxication of the sensitized cornea which is manifested clinically as interstitial keratitis. Similarly, in the uveal tract there is considerable evidence that many cases of iritis, especially of recurrent iritis, are essentially allergic, a number of them being associated with tuberculosis; an early tuberculosis infection has occurred and immunity has been acquired; on some stimulus, such as extreme exhaustion, the healed focus is lit up; owing to the acquired immunity the bacilli are disintegrated, but in their disintegration there is set free tuberculo-protein which produces an inflammatory reaction in the allergic eye. 
In the treatment of these conditions the elimination of the primary source of infection must be first attempted, this is often very difficult and requires special experience. Non-specific protein therapy by means of injections of milk, diphtheria antitoxin or tuberculin are the recommended empirical remedies the results of which the author acknowledges are irregular and impossible to foretell.

Mention is made of the use of contact glasses in neuro-paralytic keratitis and for recurrent ulcers in an anaesthetic cornea.

\section{A. F. MacCallan.}

(4) Griffith, Arthur D. (London).-Sore eyes. (Post-Graduate Lecture at Westminster Hospital). Lancet, October 14, 1933.

(4) Griffith is not here employing the use of the term " sore eyes" as applied to any internal condition, but only to the external conditions, acute and chronic conjunctivitis, blepharitis, ectropion and lacrimal obstruction. "Chronic" conjunctivitis occupies about half the total space of the article and is a most useful and instructive account of what the author calls "one of the main curses of the life of the ophthalmic surgeon." The author enters fully into the subject of infection, especially "open" and "closed" dental infection. Closed dental infection is the greater enemy. He discourages hasty decisions as to removal of teeth and points to the necessity of radiograms carefully taken and professionally studied by "a capable dental surgeon who is accustomed to interpreting dental radiograms." While this lecture does not contain much that is new to the ophthalmic surgeon, it should prove useful to the general practitioner. But the title seems rather too wide for the scope of the text.

ERnest Thomson.

\section{BOOK NOTICES}

Determination of the Sensitiveness of the Eye to Differences in the Saturation of Colours. By L. C. MARTin, F. L. WARBURTON and W. J. MORGan. Published by His Majesty's Stationery Office. 1933. Price, $1 /$-.

This is the fourth report on colour vision published by the Medical Research Council and the subject of it is treated largely from a theoretical standpoint. The problems of the mechanism of colour discrimination are investigated by experimental methods. The apparatus and its requirements, the visual conditions of observation, the experimental results and the relation of these results to the 